\title{
Evaluation of Round Window Stimulation Performance in Otosclerosis Using Finite Element Modeling
}

\author{
Shanguo Yang, ${ }^{1,2}$ Dan $\mathrm{Xu}^{1}{ }^{1}$ and Xiaole Liu ${ }^{1}$ \\ ${ }^{1}$ School of Mechatronic Engineering, China University of Mining and Technology, Xuzhou 221116, China \\ ${ }^{2}$ Jiangsu Key Laboratory of Mine Mechanical and Electrical Equipment, China University of Mining and Technology, \\ Xuzhou 221116, China \\ Correspondence should be addressed to Shanguo Yang; ysgcumt@163.com
}

Received 30 August 2015; Revised 17 January 2016; Accepted 27 January 2016

Academic Editor: Giancarlo Ferrigno

Copyright (c) 2016 Shanguo Yang et al. This is an open access article distributed under the Creative Commons Attribution License, which permits unrestricted use, distribution, and reproduction in any medium, provided the original work is properly cited.

\begin{abstract}
Round window (RW) stimulation is a new type of middle ear implant's application for treating patients with middle ear disease, such as otosclerosis. However, clinical outcomes show a substantial degree of variability. One source of variability is the variation in the material properties of the ear components caused by the disease. To investigate the influence of the otosclerosis on the performance of the RW stimulation, a human ear finite element model including middle ear and cochlea was established based on a set of microcomputerized tomography section images of a human temporal bone. Three characteristic changes of the otosclerosis in the auditory system were simulated in the FE model: stapedial annular ligament stiffness enlargement, stapedial abnormal bone growth, and partial fixation of the malleus. The FE model was verified by comparing the model-predicted results with published experimental measurements. The equivalent sound pressure (ESP) of RW stimulation was calculated via comparing the differential intracochlear pressure produced by the RW stimulation and the normal eardrum sound stimulation. The results show that the increase of stapedial annular ligament and partial fixation of the malleus decreases RW stimulation's ESP prominently at lower frequencies. In contrast, the stapedial abnormal bone growth deteriorates RW stimulation's ESP severely at higher frequencies.
\end{abstract}

\section{Introduction}

Middle ear implants (MEI) serving as an alternative treatment option for hearing loss have been a dynamic area of research during the last decade [1-5]. Unlike conventional hearing aids which use amplified sound pressure to compensate hearing impairment, the MEI always takes advantage of direct mechanical stimulation utilizing an implanted actuator to compensate hearing loss. For this reason, MEI can overcome the shortcomings of traditional hearing aids, such as higher sound distortion, limited amplification, noise and ringing, and discomfort [1].

The MEI commonly stimulates the ossicular chain; then the vibration is transmitted into the cochlea. In this process, the vibrational energy is transmitted into the cochlea through the oval window (OW). This form of MEI's application is called forward drive. However, coupling the transducer to an ossicle is difficult in ears with the middle ear disease, such as otosclerosis. To approach this issue, an alternative way of coupling sound to the cochlea by driving the round window (RW), called RW stimulation or reverse drive, was developed, and clinical studies on this novel MEI's application have been reported [6-9].

Nonetheless, clinical reports show a high variability regarding the degree of hearing compensation performance [10]. Besides, Beltrame et al. found that the actual functional gain provided by the RW stimulation is less than the theoretic expectancy [11]. To discern the factors that may cause the variability in efficacy of the RW stimulation, a lot of studies have been conducted in human temporal bone experiments. Experiments included variations such as different orientation, intervening materials between the RW and the actuator, overlaying materials, and pretension force applied on the actuator. In addition to the experimental measurements on temporal bones, the finite element models of the human ear were also used by Zhang and Gan [12] and Tian et al. [13] to investigate the effect of the actuator size and the coupling conditions, respectively. However, all of the variables are 
device-loading variables. To the authors' knowledge, there is still no report on the effect of patient-specific variables (hearing loss etiology, hearing loss configuration, etc.) on the RW stimulation performance.

Otosclerosis is a disease with abnormal growth of the ossicular bones in the middle ear. The typical changes of otosclerosis in the human ear are increased stiffness of the stapedial annular ligament [14-16], stapedial abnormal bone growth [17-19], and partial fixation of the malleus [16, 20]. These changes of ear components' properties also affect the hearing compensation performance of RW stimulation. Therefore, to figure out the influence of the otosclerosis on the RW stimulation is crucial for this type of MEI, especially for ascertaining the driving force of its actuator.

As noted above, although the device-loading variables that are leading to the variability in efficacy of the RW stimulation have been studied extensively, none of the effect concerning the otosclerosis has been reported. In this paper, we establish a 3D finite element (FE) model of the human ear to aid the analysis. By comparing the differential pressure across the partition of the cochlea under reverse and forward stimulation, the effect of otosclerosis related patientspecific variables on the performance of RW stimulation was investigated. The theoretical result is intended to support the optimization design of the actuator in order to insure sufficient compensation.

\section{Materials and Methods}

2.1. Finite Element Model of the Human Ear. A human middle ear geometric model was constructed based on a high resolution $\mathrm{CT}$ imaging data set of a human temporal bone (male, age 45, right ear). The model consists of the tympanic membrane (TM), ossicles (malleus, incus, and stapes), tendons, and ligaments. The corresponding FE mesh model was built using the FE preprocessing software Hypermesh (Altair Engineering, Tory, MI). The tympanic membrane and tympanic annulus were meshed by a total of 1569 three-node shell elements. The ossicles and suspensory ligaments/tendons were meshed by 14949 four-node tetrahedral solid elements.

The cochlea was modeled as a straight chamber with rigid wall filled with fluid. The chamber is divided by the basilar membrane (BM) and the osseous spiral lamina into two equal ducts: the scala vestibuli (SV) and the scala tympani (ST). The height of the fluid-filled SV and ST ducts was assumed to change linearly in height from $2.0 \mathrm{~mm}$ at the base to $0.4 \mathrm{~mm}$ at the apex, and the width changed linearly from $3.2 \mathrm{~mm}$ at the base to $0.65 \mathrm{~mm}$ at the apex. The length of both the SV and ST was assumed to be $37 \mathrm{~mm}$, and the fluid volumes of the SV and ST were $92.315 \mathrm{~mm}^{3}$ and $93.270 \mathrm{~mm}^{3}$, respectively. These two fluid ducts were connected at the apical end of the fluid chamber via a hole representing the helicotrema. The helicotrema was modeled as a rectangular fluid passageway with dimensions of $0.65 \times 1.6 \mathrm{~mm}$. The model of the round window membrane (RWM) has a round shape with an area of $2.1 \mathrm{~mm}^{2}$, which is similar to the mean area of $2.08 \mathrm{~mm}^{2}$ reported by Atturo et al. [21]. To avoid complications of the analysis, Reissner's membrane and the micromechanical structure of the organ of Corti were ignored in this model. This simplification method of the cochlea has been commonly accepted for the study of cochlear mechanics $[22,23]$. Besides, the width of the BM changed linearly from $150 \mu \mathrm{m}$ at the base to $500 \mu \mathrm{m}$ at the apex, and the thickness of the BM also changed linearly from $7.5 \mu \mathrm{m}$ at the base to $2.5 \mu \mathrm{m}$ at the apex [22]. At last, the BM was meshed by 482 fournode shell elements. The scala vestibuli and scala tympani were meshed by 17577 and 13802 eight-node hexahedral solid elements, respectively.

The final established human ear FE model is shown in Figure 1. The characteristic dimensions of our human ear FE model's components are also listed in Table 1 , which shows that the most dimensions of our model are within the range of published human ear data.

2.2. Material Properties. The materials of the middle ear system were assumed to be linear elastic. The material properties used for the FE model were listed in Table 2. These properties of the middle ear components were initially selected from published data [24-28]. Then, these values were turned by matching the simulated responses to the experimental responses. Poisson's ratio was assumed to be 0.3 for all of the components of the middle ear system [27]. The damping coefficients $\alpha$ and $\beta$ for all materials of the middle ear system were taken as $\alpha=0 \mathrm{~s}^{-1}, \beta=0.0001 \mathrm{~s}$ [27].

The material properties defined for the cochlea were elastic modulus, density, and Poisson's ratio. Similarly, the material properties of the cochlear components were initially assumed according to published literatures [13, 22]. Then, these parameters were checked and some of them modified in the validation process. The elastic modulus of the BM was $40 \mathrm{MPa}$ at the base, $15 \mathrm{MPa}$ at the middle, and $3 \mathrm{MPa}$ at the apex. The elastic modulus of the RW membrane and osseous spiral lamina were set to $0.3 \mathrm{MPa}$ and $1.41 \times 10^{4} \mathrm{MPa}$, respectively. The density and Poisson's ratio of the osseous spiral lamina, RW, and BM were set to $1200 \mathrm{~kg} / \mathrm{m}^{3}$ and 0.3 , and the damping parameter $\beta$ was assumed to be $1 \times 10^{-4}$ and $5 \times$ $10^{-3}$ for the BM and other solid components in the cochlea. The bulk modulus and density of the fluid in the cochlea were set to $2250 \mathrm{MPa}$ and $1000 \mathrm{~kg} / \mathrm{m}^{3}$, respectively. The material properties used for the cochlea were summarized in Table 3.

2.3. Boundary Conditions. The end nodes of all the muscles and ligaments were fixed to zero displacement, including the periphery of the stapedial annulus ligament. The outer edge of tympanic membrane annulus was defined as the fixed constraint. The surfaces of the elements that represent the bony wall of the cochlea were set as rigid walls. A uniform pressure was applied on the eardrum to simulate the sound stimulus of normal human ear.

2.4. FE Modeling of the RW Stimulation. As our main concern is the influence of the otosclerosis on the RW stimulation's performance, not the effects of the MEI's parameters, the actual structure of the MEI's actuator was not modeled in our model for simplification. The RW stimulation was simulated by applying driving force onto the surface of RW along the normal direction of the RW. 


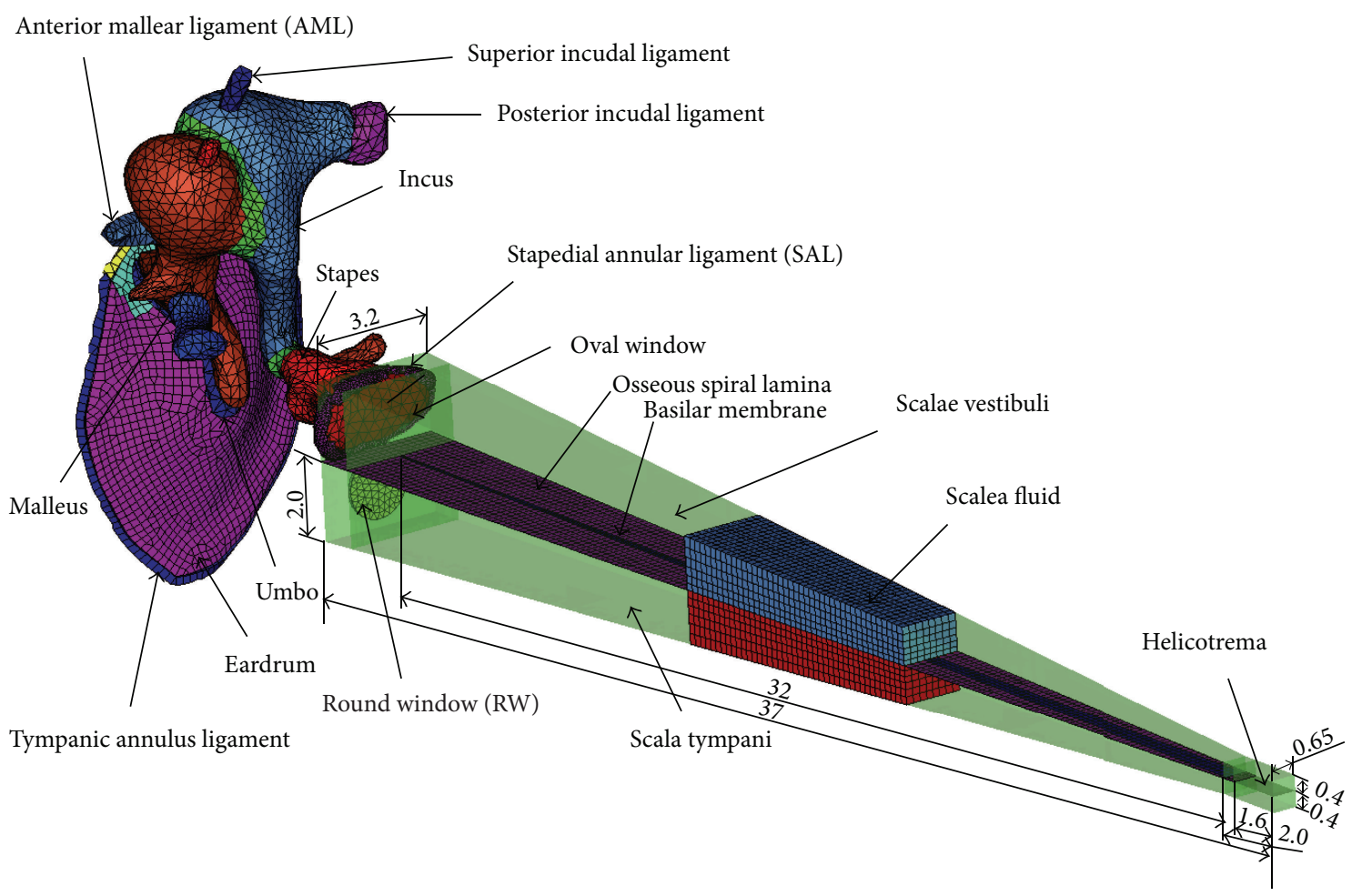

FIGURE 1: Finite element model of human ear with middle ear components and simplified cochlea.

In the design of the middle ear implant, it is important to quantify its hearing compensating performance. The stapes displacement is usually used as the reference parameter in this evaluating process. However, the stapes lies outside the cochlea. Its vibration cannot reflect the inner dynamical properties of the cochlea accurately. As the intracochlear differential pressure across the cochlear partition at the base of the cochlea is proved to be a sensitive measure of the cochlear input [29] and the vibration of the basilar membrane can be deduced by the intracochlear pressure $[30,31]$, the intracochlear pressure was measured by many researchers to uncover the mechanism of cochlear mechanics [29, 32, 33] and evaluate the middle ear implant's performance $[13,34$, 35]. Thus, in this paper, we also used the intracochlear pressure to assess the round window stimulation's performance. Specifically, we used the equivalent sound pressure (ESP), which is expressed as [13]

$$
P_{\mathrm{eq}}=90+20 \log \left(\frac{\left|P_{\mathrm{SV}}^{R}-P_{\mathrm{ST}}^{R}\right|}{\left|P_{\mathrm{SV}}^{F}-P_{\mathrm{ST}}^{F}\right|}\right) \text {, }
$$

where $P_{\mathrm{SV}}^{F}, P_{\mathrm{ST}}^{F}$ are the fluid pressures in the cochlear scala vestibule and scala tympani under forward sound stimulation ( $90 \mathrm{~dB}$ SPL applied onto the eardrum) and $P_{\mathrm{SV}}^{R}, P_{\mathrm{ST}}^{R}$ are the fluid pressures in the scala vestibule and scala tympani under reverse RW stimulation ( $50 \mu \mathrm{N}$ driving force applied onto the round window membrane $[12,13])$. The detailed derivation of (1) can be found in [13].
2.5. Simulation of Otosclerosis in FE Model. Otosclerosis is a disease with abnormal growth of the ossicular bones in the middle ear. The typical changes of otosclerosis in the human ear are increased stiffness of the stapedial annular ligament, stapedial abnormal bone growth, and partial fixation of the malleus. To simulate the enlargement of the stapedial annular ligament's stiffness and the partial fixation of the malleus, the elastic modulus of the normal stapedial annular ligament (SAL) and the anterior mallear ligament (AML) were increased by a factor of 10 and 100, respectively. In terms of the stapedial abnormal bone growth, we boosted the FE model's stapes mass by a factor of 5 to mimic this symptom, based on the literature [19].

\section{Results}

3.1. Convergence Test. Convergence test is used to investigate what mesh resolution should be used in our FE models. We established a set of 3 models in which the uniform sizes of the elements are $0.3 \mathrm{~mm}, 0.2 \mathrm{~mm}$, and $0.15 \mathrm{~mm}$, respectively. These models were compared based on the model-predicted stapes displacement under $90 \mathrm{~dB}$ sound pressure applied at the eardrum. Result of this test is plotted in Figure 2. It shows that these three models have almost the same stapes displacement curves. The maximum difference between the $0.2-\mathrm{mm}$ model and the $0.15-\mathrm{mm}$ model was less than $0.7 \%$. This result implied that the $0.2-\mathrm{mm}$ model provides enough accuracy and it is the one used for the remaining simulations.

3.2. Human Ear FE Model Verification. In order to establish the extent to which the prediction of the human ear FE 
TABLE 1: Dimensions of the human ear finite element model.

\begin{tabular}{|c|c|c|}
\hline Structure & Our model & Published data \\
\hline \multicolumn{3}{|l|}{ Eardrum } \\
\hline Diameter along manubrium & $8.99 \mathrm{~mm}$ & $8.0-10.0 \mathrm{~mm}[47]$ \\
\hline $\begin{array}{l}\text { Diameter perpendicular to } \\
\text { manubrium }\end{array}$ & $7.75 \mathrm{~mm}$ & $7.5-9.0 \mathrm{~mm}[47]$ \\
\hline Thickness & $0.1 \mathrm{~mm}$ & $0.1 \mathrm{~mm}[47]$ \\
\hline \multicolumn{3}{|l|}{ Malleus } \\
\hline Total length & $7.67 \mathrm{~mm}$ & 7.6-9.1 mm [47] \\
\hline \multicolumn{3}{|l|}{ Incus } \\
\hline Length along long process & $7.10 \mathrm{~mm}$ & $7.0 \mathrm{~mm}[47]$ \\
\hline Length along short process & $4.89 \mathrm{~mm}$ & $5.0 \mathrm{~mm}[47]$ \\
\hline \multicolumn{3}{|l|}{ Stapes } \\
\hline Height & $3.75 \mathrm{~mm}$ & $2.5-4.0 \mathrm{~mm}[47]$ \\
\hline Length of footplate & $2.95 \mathrm{~mm}$ & $2.64-3.36 \mathrm{~mm}[47]$ \\
\hline Width of footplate & $1.51 \mathrm{~mm}$ & $0.7-1.66 \mathrm{~mm}[47]$ \\
\hline \multicolumn{3}{|l|}{ Cochlea } \\
\hline Length of cochlea & $37 \mathrm{~mm}$ & $29.07-37.45 \mathrm{~mm}[48$ \\
\hline Length of BM & $34 \mathrm{~mm}$ & $35 \mathrm{~mm}[49]$ \\
\hline Width of BM at base & $0.15 \mathrm{~mm}$ & $0.1 \mathrm{~mm}[49]$ \\
\hline Width of BM at apex & $0.5 \mathrm{~mm}$ & $0.5 \mathrm{~mm}[49]$ \\
\hline Thickness of BM at base & $7.5 \mu \mathrm{m}$ & $7.5 \mu \mathrm{m}[50]$ \\
\hline Thickness of BM at apex & $2.5 \mu \mathrm{m}$ & $2.5 \mu \mathrm{m}[50]$ \\
\hline Volume of scala vestibuli & $92.315 \mathrm{~mm}^{3}$ & $90.8463 \mathrm{~mm}^{3}[51]$ \\
\hline Volume of scala tympani & $93.270 \mathrm{~mm}^{3}$ & $91.2044 \mathrm{~mm}^{3}[51]$ \\
\hline Area of RWM & $2.1 \mathrm{~mm}^{2}$ & $2.08 \mathrm{~mm}^{2}[21]$ \\
\hline
\end{tabular}

model accords with reality, comparisons against four sets of experimental studies were done. Gan et al. experimental data of stapes footplate displacement [36] and umbo displacement [37] obtained from temporal bones were initially selected for the model verification. A uniform pressure of $90 \mathrm{~dB}$ SPL on the lateral side of the eardrum was applied to our human ear FE model. A harmonic analysis was conducted on the model. As the most important frequencies for speech fall into the $250-6000 \mathrm{~Hz}$ range, and the range between $250 \mathrm{~Hz}$ and $8000 \mathrm{~Hz}$ is normally used in the audiogram, the harmonic analysis focused on the range between $200 \mathrm{~Hz}$ and $8000 \mathrm{~Hz}$. The model-predicted results were plotted with the experimental curves in Figures 3 and 4. Figure 3 shows that our model-predicted stapes displacement curve lies close to the mean of the experimental curves. Likewise, the FE modelpredicted umbo displacement is close to the mean experimental curve as shown in Figure 4. But, at high frequency, both the model-predicted displacements of the stapes and the umbo are small compared to their corresponding mean experimental curves. This discrepancy may be attributed to the constant elastic modulus and Rayleigh type damping we used, which makes the damping of the soft tissues in our model proportional to the frequency as well as too high at the high frequency [14].

The cochlear input impedance, defined as the ratio of sound pressure produced in the scala vestibuli at the oval window to the volume velocity of scalae fluid at the oval
TABLE 2: Material properties of the middle ear components.

\begin{tabular}{|c|c|c|}
\hline Structure & $\begin{array}{l}\text { Young's modulus } \\
\left(\mathrm{N} / \mathrm{m}^{2}\right)\end{array}$ & $\begin{array}{l}\text { Density } \\
\left(\mathrm{kg} / \mathrm{m}^{3}\right)\end{array}$ \\
\hline \multicolumn{3}{|l|}{ Eardrum } \\
\hline Pars flaccida & $1.00 \times 10^{7}$ & $1.20 \times 10^{3}$ \\
\hline Pars tensa & $3.20 \times 10^{7}$ & $1.20 \times 10^{3}$ \\
\hline \multicolumn{3}{|l|}{ Ossicles } \\
\hline \multicolumn{3}{|l|}{ Malleus } \\
\hline Head & $1.41 \times 10^{10}$ & $2.55 \times 10^{3}$ \\
\hline Neck & $1.41 \times 10^{10}$ & $4.53 \times 10^{3}$ \\
\hline Handle & $1.41 \times 10^{10}$ & $3.70 \times 10^{3}$ \\
\hline \multicolumn{3}{|l|}{ Incus } \\
\hline Body & $1.41 \times 10^{10}$ & $2.36 \times 10^{3}$ \\
\hline Short process & $1.41 \times 10^{10}$ & $2.26 \times 10^{3}$ \\
\hline Long process & $1.41 \times 10^{10}$ & $5.08 \times 10^{3}$ \\
\hline Stapes & $1.41 \times 10^{10}$ & $2.20 \times 10^{3}$ \\
\hline \multicolumn{3}{|l|}{ Joint } \\
\hline Incudomalleolar joint & $1.41 \times 10^{10}$ & $2.39 \times 10^{3}$ \\
\hline Incudostapedial joint & $4.00 \times 10^{6}$ & $1.20 \times 10^{3}$ \\
\hline \multicolumn{3}{|l|}{ Ligament/tendon } \\
\hline Tympanic annulus ligament & $4.00 \times 10^{5}$ & $1.20 \times 10^{3}$ \\
\hline Superior mallear ligament & $4.90 \times 10^{6}$ & $1.20 \times 10^{3}$ \\
\hline Lateral mallear ligament & $6.70 \times 10^{6}$ & $1.20 \times 10^{3}$ \\
\hline Anterior mallear ligament & $2.10 \times 10^{7}$ & $1.20 \times 10^{3}$ \\
\hline Superior incudal ligament & $4.90 \times 10^{6}$ & $1.20 \times 10^{3}$ \\
\hline Posterior incudal ligament & $6.50 \times 10^{6}$ & $1.20 \times 10^{3}$ \\
\hline Stapedial annulus ligament & $4.10 \times 10^{5}$ & $1.20 \times 10^{3}$ \\
\hline Tensor tympani tendon & $2.60 \times 10^{6}$ & $1.20 \times 10^{3}$ \\
\hline Stapedial tendon & $5.20 \times 10^{5}$ & $1.20 \times 10^{3}$ \\
\hline
\end{tabular}

TABLE 3: Material properties of the cochlear components.

\begin{tabular}{lcc}
\hline Structure & Our model & Published data \\
\hline $\begin{array}{l}\text { Round window membrane } \\
\text { Density }\left(\mathrm{kg} / \mathrm{m}^{3}\right)\end{array}$ & $1.20 \times 10^{3}$ & $1.20 \times 10^{3}[22]$ \\
Young's modulus (MPa) & 0.3 & $0.3[13], 0.35[22]$ \\
Basilar membrane (BM) & & \\
Density $\left(\mathrm{kg} / \mathrm{m}^{3}\right)$ & $1.20 \times 10^{3}$ & $1.20 \times 10^{3}[22]$ \\
Young's modulus (MPa) & & \\
$\quad$ At the base & 40 & $40[13], 50[22]$ \\
$\quad$ In the middle & 15 & $15[22]$ \\
$\quad$ At the apex & 3 & $3[22]$ \\
Perilymph fluid & & $1.00 \times 10^{3}[22]$ \\
Density $\left(\mathrm{kg} / \mathrm{m}^{3}\right)$ & $1.00 \times 10^{3}$ & $2.20 \times 10^{3}[22]$ \\
Bulk modulus $(\mathrm{MPa})$ & $2.25 \times 10^{3}$ & \\
Osseous spiral lamina & & $1.20 \times 10^{3}[22]$ \\
Density $\left(\mathrm{kg} / \mathrm{m}^{3}\right)$ & $1.20 \times 10^{3}$ & $1.41 \times 10^{4}[22]$ \\
Young's modulus $(\mathrm{MPa})$ & $1.41 \times 10^{4}$ &
\end{tabular}

window, is an important parameter reflecting the sound energy transfer property from the middle ear into the cochlea. Thus, the experimental data of the cochlea input impedance 


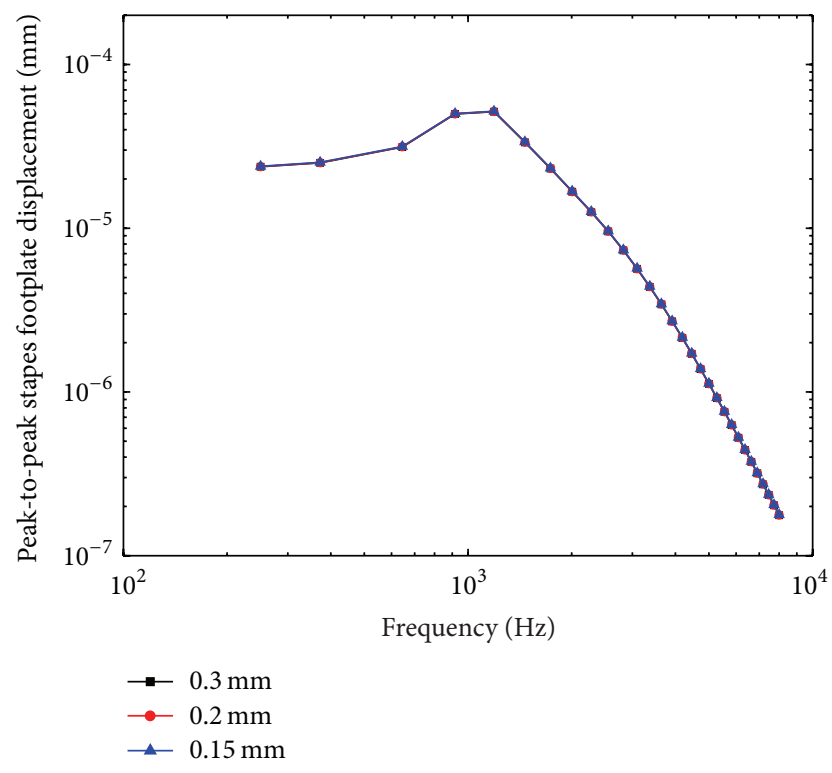

FIGURE 2: Convergence test for the human ear FE model.

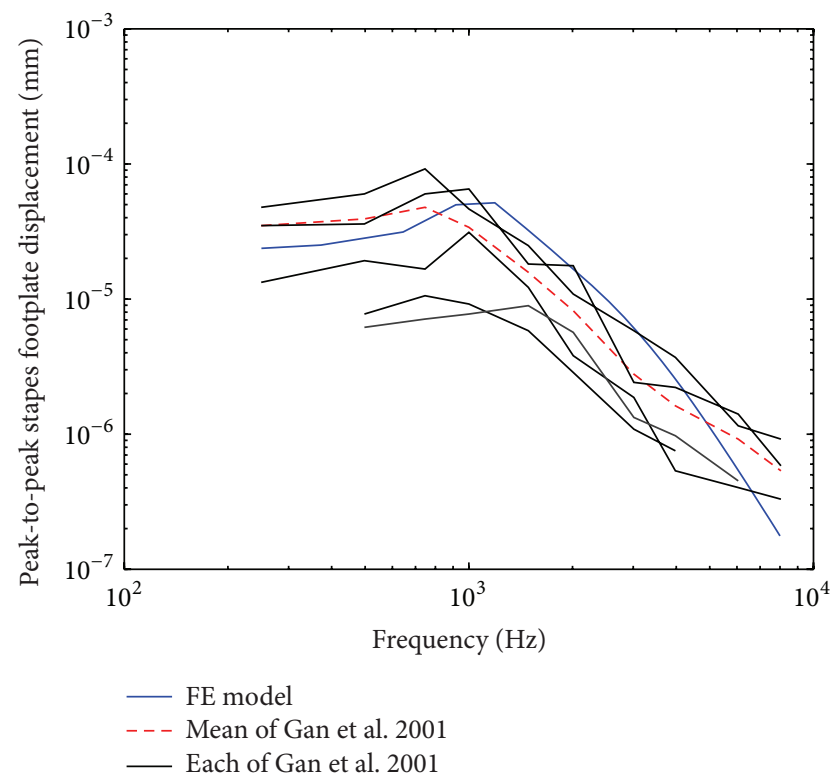

FIGURE 3: Comparison of the FE model-predicted stapes footplate displacement with the experimental data.

published by Puria et al. [38] and Aibara et al. [39] were also selected for current model evaluation. The model-predicted cochlear input impedance was plotted with the experimental curves in Figure 5. As shown in Figure 5, the model-predicted results are in reasonable agreement with the published data in terms of overall response trends. The model-derived value deceased from $100 \mathrm{~Hz}$ to $380 \mathrm{~Hz}$ with a minimum of $6.5 \mathrm{G} \Omega$ at $380 \mathrm{~Hz}$. However, at frequencies above $380 \mathrm{~Hz}$, the model-derived impedance increases gradually with the frequency. In general, the FE results are more consistent with the impedance data obtained by Puria et al., especially at frequencies higher than $1 \mathrm{kHz}$.

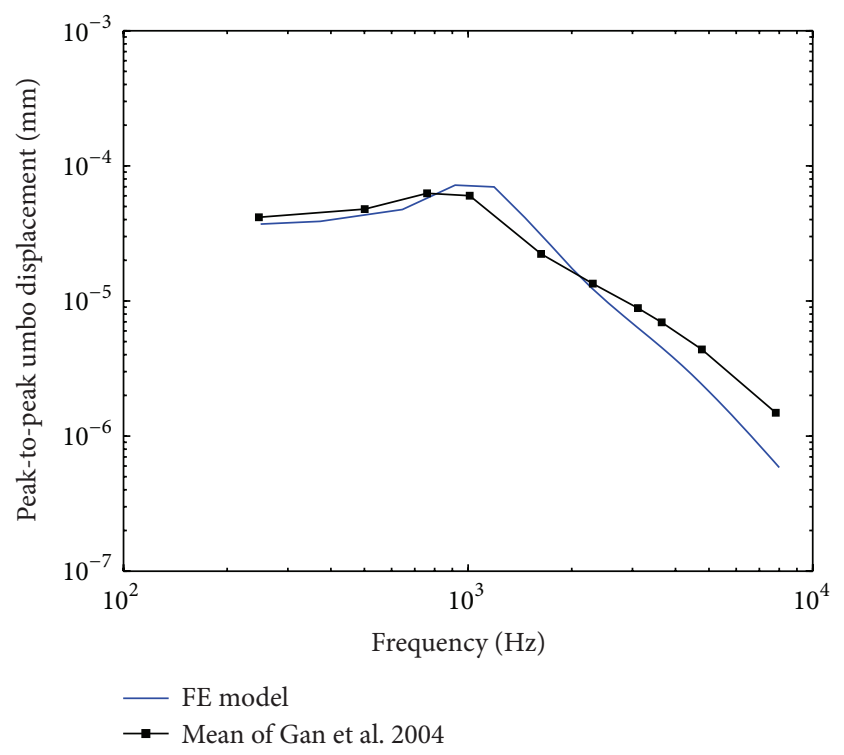

FIGURE 4: Comparison of the FE model-predicted umbo displacement with the experimental data.

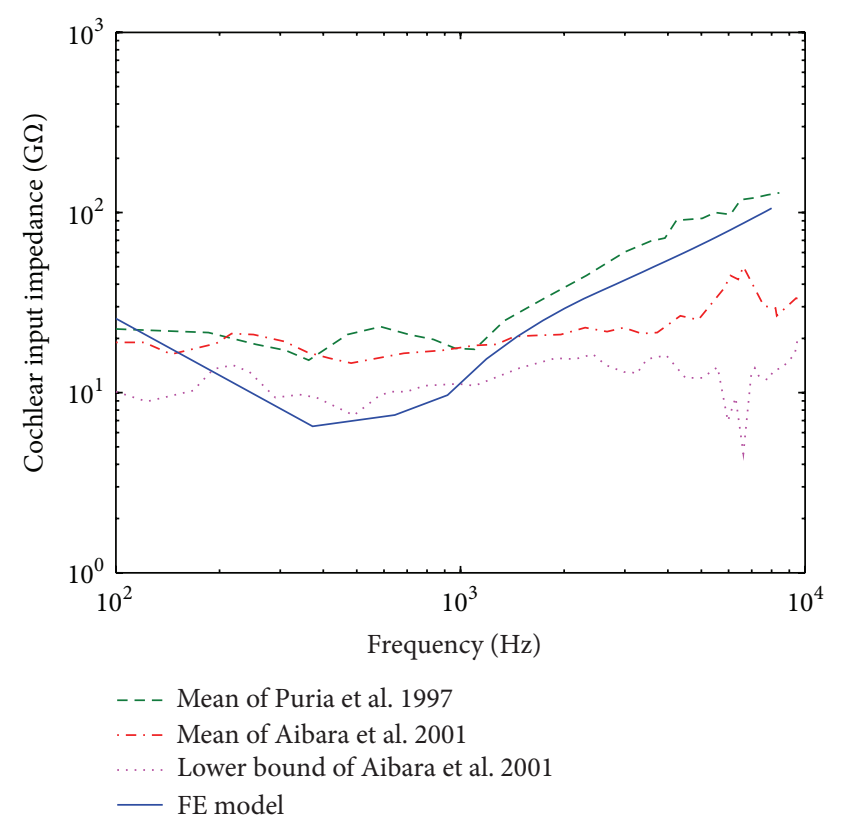

FIGURE 5: Comparison of the FE model-predicted cochlear input impedance with that measured on human temporal bones by Puria et al. [38] and Aibara et al [39].

Cochlear best frequency (BF) map indicates the frequency corresponding to the peak BM vibration as a function of location along the BM length. This BF map demonstrates the cochlear frequency selectivity. Figure 6 shows our modelpredicted BF map compared with the experimental curves reported by Von Bekesy [40] and Kringlebotn et al. [41]. As shown in Figure 6, a reasonable agreement exists between our model-predicted results and these measurements.

These above comparisons show that our human ear FE model's predictions, in general, match experimental results 


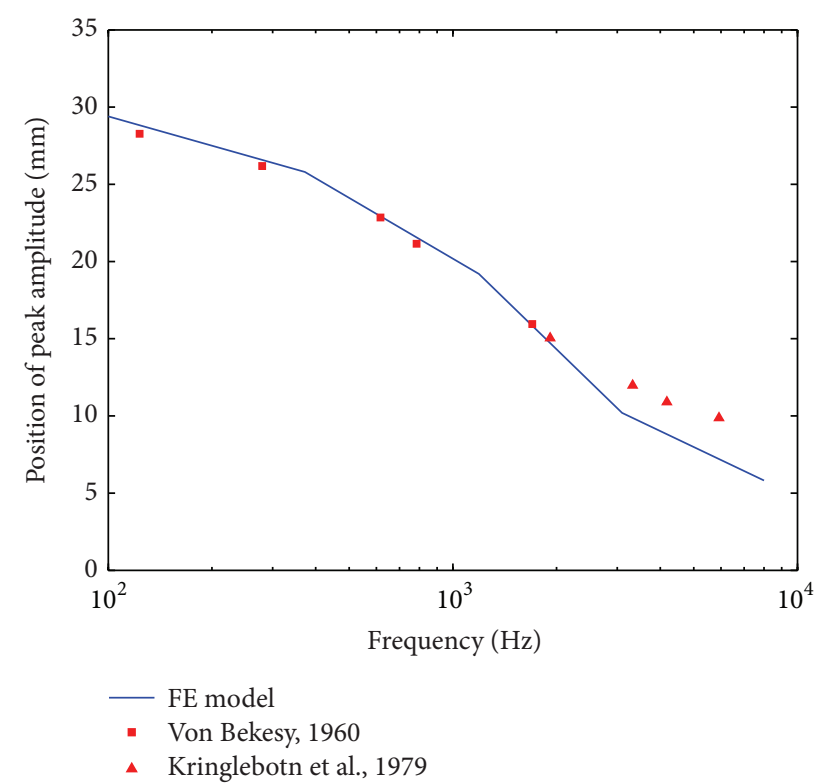

Figure 6: Comparison of the FE model-predicted cochlear best frequency map with experimental reports.

obtained from human temporal bones. Therefore, this FE model is able to predict biomechanical characteristics of the human ear system.

3.3. Effect of the SAL Stiffness Enlargement on the RW Stimulation Performance. The effect of the SAL stiffness enlargement on the round window stimulation performance was investigated by comparing the ESP corresponding to an excitation force of $50 \mu \mathrm{N}$ on the round window membrane under different SAL elastic modulus. To study the effect of the stiffness enhancement related to the otosclerosis, we increased the elastic modulus of the SAL by 10 -fold [42]. Figure 7(a) shows that the increase of the SAL stiffness decreases the ESP of the RW stimulation over the entire frequencies. Besides, this decrease is significant at lower frequencies (below $3 \mathrm{kHz}$ ). The maximum decline of the ESP is about $20 \mathrm{~dB}$ at $1400 \mathrm{~Hz}$ (Figure 7(b)). At higher frequencies $(>3 \mathrm{kHz})$, the adverse effect of the SAL stiffness enlargement on the ESP decreased with the increase of the frequency.

3.4. Effect of the Stapedial Abnormal Bone Growth on the $R W$ Stimulation Performance. The stapedial abnormal bone growth was simulated by increasing the mass of the stapes [19]. And the influence of stapes mass change on the round window stimulation performance was studied (Figure 8). By increasing the density of stapes from $2.2 \times 10^{3} \mathrm{~kg} / \mathrm{m}^{3}$ to $1.1 \times$ $10^{4} \mathrm{~kg} / \mathrm{m}^{3}$, we got the simulated mass of the stapes boosted by 5 -fold. The model-predicted result (Figure 8(a)) shows that the increase of the stapes mass has little impact on the ESP at lower frequencies (below $900 \mathrm{~Hz}$ ). However, when the frequency increases, the ESP starts to decrease with the addition of the stapes mass. The maximum drop in ESP is around $6.2 \mathrm{~dB}$ at $8000 \mathrm{~Hz}$ (Figure 8(b)).
3.5. Effect of the Partial Fixation of the Malleus on the RW Simulation Performance. The effect of the partial fixation of the malleus on the RW stimulation performance was investigated by change of the elastic modulus of the AML [16]. To simulate partial mallear fixation with a calcified AML, the elastic modulus of normal AML $\left(2.1 \times 10^{7} \mathrm{MPa}\right)$ was increased by a factor of 1000 [16]. Figure 9 shows the corresponding model-predicted results. Similar to SAL stiffness's effect, the increase of the AML elastic modulus does not impact the ESP significantly at higher frequencies above $3000 \mathrm{~Hz}$ (Figure 9(a)). However, the RW stimulation ESP with AML enlargement showed a significant drop in the lower frequencies (below $3000 \mathrm{~Hz}$ ), especially in the range of $1000 \mathrm{~Hz}$ to $2000 \mathrm{~Hz}$. The maximum drop in ESP is about $15.4 \mathrm{~dB}$ at $1500 \mathrm{~Hz}$, where a notch is present (Figure 9(b)).

\section{Discussion}

Coupling the MEI's actuator directly to the cochlear round window, which bypasses the ossicular chain, is a new application of middle ear implant for the treatment of patients with middle ear disease. Clinical reports show a considerable variability $(30 \mathrm{~dB})$ in patients' outcomes. Potential variables, which have been identified as the reason for this outcomes, can be classified into device-loading and patient-specific variables. The main device-loading variables include the different orientation of the IMEHD's actuator, the intervening materials between the RW and the actuator, the overlaying materials, and the loading pressure applied to the RW. Lupo et al's experimental report [43] demonstrates that the loading pressure and angle of approach do not have a significant effect on the MEI's performance. Based on temporal bone experiment, Arnold et al.s study [44] indicates that underlying a connective tissue between the RW and the actuator can get a substantial improvement of up to $13 \mathrm{~dB}$. Besides, comparing with the effect of the intervening materials, the influence of the overlaying materials is considerably smaller. All of above researches only focus on the device-loading variables.

Considering that the treatment of otosclerosis is one of the main targets of the RW stimulation, the patient-specific variables corresponding to the otosclerosis were also investigated in this paper. Three typical changes of ear components corresponding to otosclerosis in the auditory system were studied in our FE model: stapedial annular ligament stiffness enlargement, stapedial abnormal bone growth, and partial fixation of the malleus.

Based on experiments and middle ear mechanical models, Huber et al. [16] and Feng and Gan [42] both found that the SAL stiffness enlargement deteriorates normal hearing perception dramatically at lower frequencies. In terms of its influence on RW stimulation, our results show the same trend; that is, the SAL stiffness augment mainly deceased RW simulation performance at lower frequencies below $3000 \mathrm{~Hz}$ (about $20 \mathrm{~dB}$ at $1400 \mathrm{~Hz}$ ). The enlargement of SAL stiffness shows a similar influence on normal hearing perception and RW stimulation performance may be attributed to the fact that the stiffness impedes the motion at low frequencies in dynamic system. Besides, the $20 \mathrm{~dB}$ deterioration is considerably large regarding the clinical reported variability in RW 


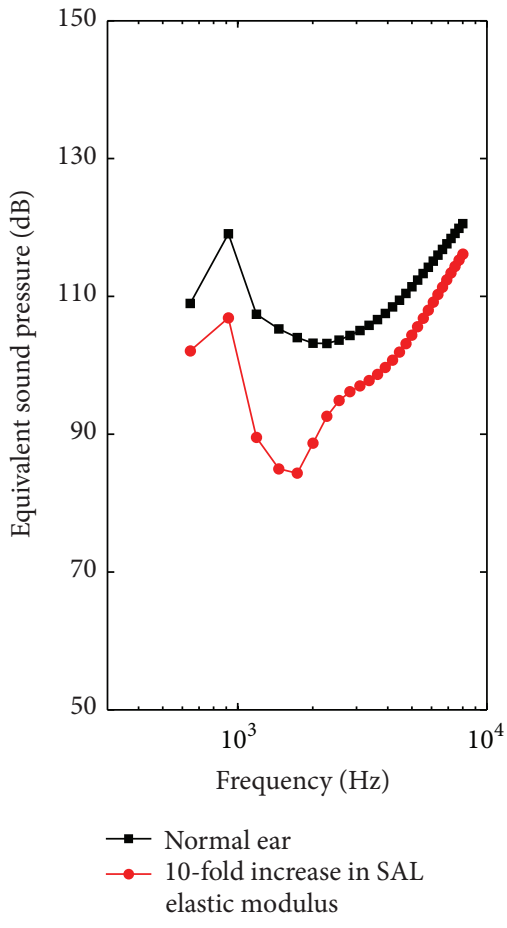

(a)

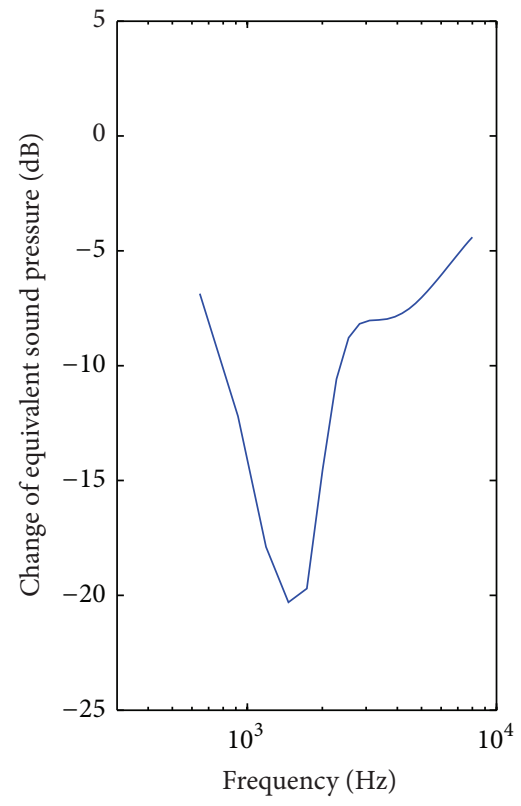

(b)

FIGURE 7: The effect of the SAL stiffness enlargement on the RW stimulation performance. (a) Equivalent sound pressure (ESP). (b) Change of the equivalent sound pressure with the augment of the SAL elastic modulus.

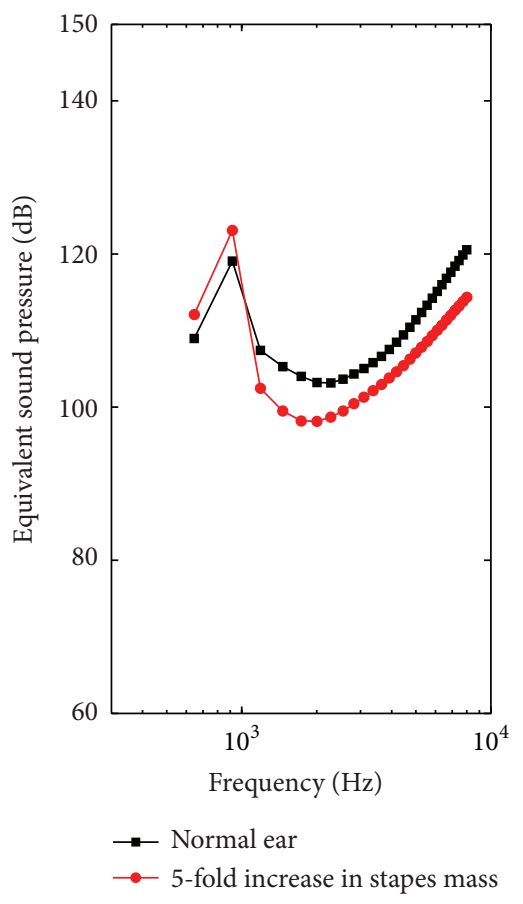

(a)

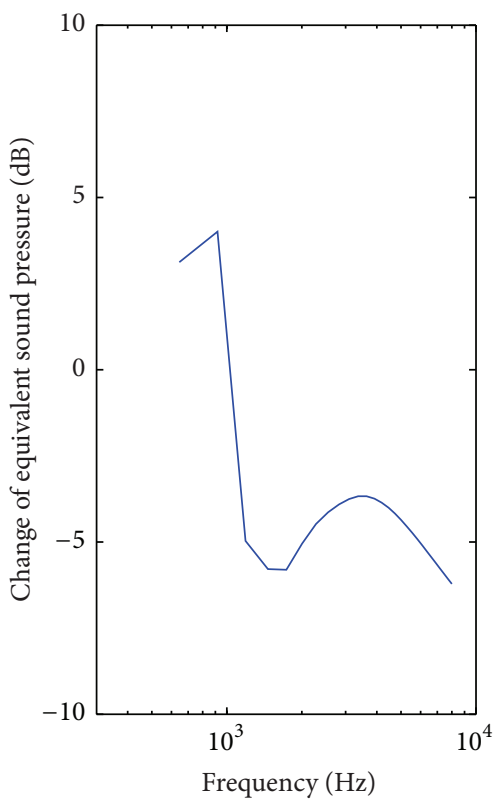

(b)

FIGURE 8: The effect of the stapedial mass augment on the RW stimulation performance. (a) Equivalent sound pressure (ESP). (b) Change of the equivalent sound pressure with the augment of the stapedial mass. 


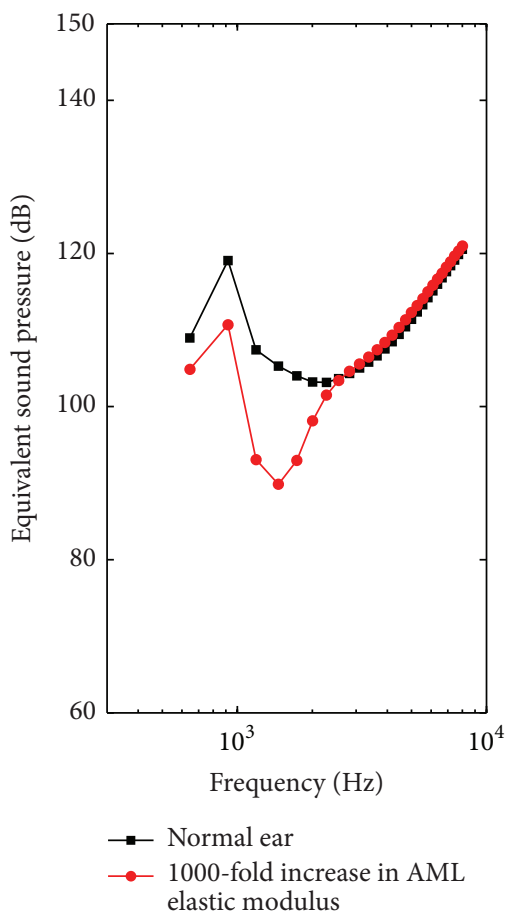

(a)

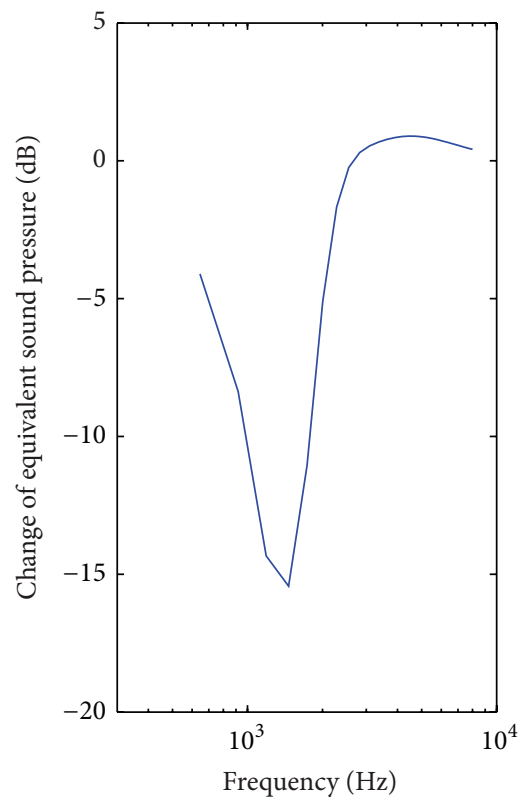

(b)

FIGURE 9: The effect of partial fixation of the malleus on the RW stimulation performance. (a) Equivalent sound pressure (ESP). (b) Change of the equivalent sound pressure with the 1000 -fold increase in AML elastic modulus.

stimulation's outcomes $(30 \mathrm{~dB})$. Therefore, to cure this kind of disease, the influence of the SAL stiffness enlargement cannot be ignored, and the corresponding MEI's driving force should be strengthened prominently at lower frequencies in the design of this type of MEI.

With regard to the stapedial abnormal bone growth, we increased the mass of stapes by 5 times to simulate this symptom [19]. Our results show that the augment of stapedial mass increased the RW stimulation performance slightly at lower frequencies below $1000 \mathrm{~Hz}$, while decreasing the performance severely at higher frequencies above $1200 \mathrm{~Hz}$. This is mainly because the adding mass of the stapes shifts the resonance of the middle ear system toward lower frequencies. The maximum drop in ESP, which is around $6.2 \mathrm{~dB}$ at $8000 \mathrm{~Hz}$, is relatively small compared with the influence of the enlargement of SAL stiffness $(20 \mathrm{~dB})$. To simulate the symptom of partial mallear fixation, Huber et al. increased the AML's elastic modulus by a factor of 1000 [16]. In this paper, we utilized the same method to model this disease. Similar to the influence of the SAL stiffness enlargement, the partial mallear fixation also deteriorates RW stimulation performance prominently at lower frequencies below $3000 \mathrm{~Hz}$. The maximum drop in ESP is about $15.4 \mathrm{~dB}$. This deterioration level is much larger than the stapedial mass's influence but comparable to the effect of the SAL stiffness enlargement.

The above results demonstrate that the typical characteristics of the otosclerosis do decrease the RW stimulation performance, particularly at lower frequencies below $3000 \mathrm{~Hz}$. Considering that we perceive the speech mainly in the frequency range of $500 \mathrm{~Hz}$ to $3000 \mathrm{~Hz}[45,46]$, this deterioration on lower frequency region (below $3000 \mathrm{~Hz}$ ) is detrimental to the patients' speech understanding. Thus, the driving capacity of the RW stimulation should be enhanced, particularly at lower frequencies below $3000 \mathrm{~Hz}$.

\section{Conclusion}

In this study, a FE model of the human ear including the middle ear and cochlea was used to investigate the influence of otosclerosis on RW stimulation. The FE model was constructed based on a complete set of computerized tomography section images of a right ear by reverse engineering technology, and its validity was verified by comparing the model-predicted results with published experimental data. The results show that the enlargements of stapedial annular ligament and partial fixation of the malleus decrease RW stimulation's ESP prominently at lower frequencies. In contrast, the stapedial abnormal bone growth deteriorates RW stimulation's ESP severely at higher frequencies.

\section{Conflict of Interests}

The authors declare that there is no conflict of interests regarding the publication of this paper.

\section{Acknowledgments}

The research work was supported by National Natural Science Foundation of China (Grant no. 51305442), the Jiangsu Provincial Natural Science Foundation (Grant no. 
BK20130194), Specialized Research Fund for the Doctoral Program of Higher Education (Grant no. 20130095120010), and the Priority Academic Program Development of Jiangsu Higher Education Institutions.

\section{References}

[1] C. N. Kahue, M. L. Carlson, J. A. Daugherty, D. S. Haynes, and M. E. Glasscock, "Middle ear implants for rehabilitation of sensorineural hearing loss: a systematic review of FDA approved devices," Otology \& Neurotology, vol. 35, no. 7, pp. 1228-1237, 2014.

[2] H. Liu, N. Ta, X. Ming, and Z. Rao, "Design of floating mass type piezoelectric actuator for implantable middle ear hearing devices," Chinese Journal of Mechanical Engineering, vol. 22, no. 2, pp. 221-226, 2009.

[3] S. Hamanishi, T. Koike, H. Matsuki, and H. Wada, "A new electromagnetic hearing aid using lightweight coils to vibrate the ossicles," IEEE Transactions on Magnetics, vol. 40, no. 5, pp. 3387-3393, 2004.

[4] C.-F. Lee, C.-H. Shih, J.-F. Yu, J.-H. Chen, Y.-F. Chou, and T.C. Liu, "A novel opto-electromagnetic actuator coupled to the tympanic membrane," Journal of Biomechanics, vol. 41, no. 16, pp. 3515-3518, 2008.

[5] H. Liu, Z. Rao, X. Huang, G. Cheng, J. Tian, and N. Ta, "An incus-body driving type piezoelectric middle ear implant design and evaluation in 3D computational model and temporal bone," The Scientific World Journal, vol. 2014, Article ID 121624, 8 pages, 2014.

[6] L. Colletti, M. Mandalà, and V. Colletti, "Long-term outcome of round window vibrant soundbridge implantation in extensive ossicular chain defects," Otolaryngology-Head and Neck Surgery, vol. 149, no. 1, pp. 134-141, 2013.

[7] D. Bernardeschi, C. Hoffman, T. Benchaa et al., "Functional results of vibrant soundbridge middle ear implants in conductive and mixed hearing losses," Audiology and Neurotology, vol. 16, no. 6, pp. 381-387, 2011.

[8] C. Martin, A. Deveze, C. Richard et al., "European results with totally implantable carina placed on the round window: 2-year follow-up," Otology and Neurotology, vol. 30, no. 8, pp. 11961203, 2009.

[9] V. Colletti, S. D. Soli, M. Carner, and L. Colletti, "Treatment of mixed hearing losses via implantation of a vibratory transducer on the round window," International Journal of Audiology, vol. 45, no. 10, pp. 600-608, 2006.

[10] G. M. Sprinzl, A. Wolf-Magele, J. Schnabl, and V. Koci, "The active middle ear implant for the rehabilitation of sensorineural, mixed and conductive hearing losses," Laryngo-Rhino-Otologie, vol. 90, no. 9, pp. 560-572, 2011.

[11] A. M. Beltrame, A. Martini, S. Prosser, N. Giarbini, and C. Streitberger, "Coupling the vibrant soundbridge to cochlea round window: auditory results in patients with mixed hearing loss," Otology and Neurotology, vol. 30, no. 2, pp. 194-201, 2009.

[12] X. Zhang and R. Z. Gan, "A comprehensive model of human ear for analysis of implantable hearing devices," IEEE Transactions on Biomedical Engineering, vol. 58, no. 10, pp. 3024-3027, 2011.

[13] J. Tian, X. Huang, Z. Rao, N. Ta, and L. Xu, "Finite element analysis of the effect of actuator coupling conditions on round window stimulation," Journal of Mechanics in Medicine and Biology, vol. 15, no. 4, Article ID 1550048, 19 pages, 2015.
[14] X. Zhang and R. Z. Gan, "Finite element modeling of energy absorbance in normal and disordered human ears," Hearing Research, vol. 301, pp. 146-155, 2013.

[15] J.-Y. Min, W.-H. Chung, W. Y. Lee et al., "Otosclerosis: incidence of positive findings on temporal bone computed tomography (TBCT) and audiometric correlation in Korean patients," Auris Nasus Larynx, vol. 37, no. 1, pp. 23-28, 2010.

[16] A. Huber, T. Koike, H. Wada, V. Nandapalan, and U. Fisch, "Fixation of the anterior mallear ligament: diagnosis and consequences for hearing results in stapes surgery," Annals of Otology, Rhinology and Laryngology, vol. 112, no. 4, pp. 348-355, 2003.

[17] K. H. Brookler, "Clinical findings in a patient with aural fullness," Ear, Nose and Throat Journal, vol. 87, no. 2, pp. 74-75, 2008.

[18] M. Miller and J. Schein, "Selected complex auditory disorders," Journal of Rehabilitation Research \& Development, vol. 4, no. 24, pp. 1-8, 2005.

[19] H. Frost, "Observations on the fundamental nature of otosclerosis," in Otosclerosis, H. Schuknecht, Ed., Little, Brown and Company, Boston, Mass, USA, 1962.

[20] U. Fisch, G. Ö. Acar, and A. M. Huber, "Malleostapedotomy in revision surgery for otosclerosis," Otology \& Neurotology, vol. 22, no. 6, pp. 776-785, 2001.

[21] F. Atturo, M. Barbara, and H. Rask-Andersen, "Is the human round window really round? An anatomic study with surgical implications," Otology and Neurotology, vol. 35, no. 8, pp. 13541360, 2014.

[22] R. Z. Gan, B. P. Reeves, and X. L. Wang, "Modeling of sound transmission from ear canal to cochlea," Annals of Biomedical Engineering, vol. 35, no. 12, pp. 2180-2195, 2007.

[23] C. R. Steele and K.-M. Lim, "Cochlear model with threedimensional fluid, inner sulcus and feed-forward mechanism," Audiology and Neuro-Otology, vol. 4, no. 3-4, pp. 197-203, 1999.

[24] H. Liu, S. Ge, G. Cheng, J. Yang, Z. Rao, and X. Huang, "The effect of implantable transducers on middle ear transfer function: a comparative numerical analysis," Journal of Mechanics in Medicine and Biology, pp. 1-16, 2016.

[25] R. Z. Gan, B. Feng, and Q. Sun, "Three-dimensional finite element modeling of human ear for sound transmission," Annals of Biomedical Engineering, vol. 32, no. 6, pp. 847-859, 2004.

[26] T. Koike, H. Wada, and T. Kobayashi, "Modeling of the human middle ear using the finite-element method," Journal of the Acoustical Society of America, vol. 111, no. 3, pp. 1306-1317, 2002.

[27] Q. Sun, R. Z. Gan, K.-H. Chang, and K. J. Dormer, "Computerintegrated finite element modeling of human middle ear," Biomechanics and Modeling in Mechanobiology, vol. 1, no. 2, pp. 109-122, 2002.

[28] H. Liu, S. Ge, G. Cheng, J. Yang, Z. Rao, and X. Huang, "Transducer type and design influence on the hearing loss compensation behaviour of the electromagnetic middle ear implant in a finite element analysis," Advances in Mechanical Engineering, vol. 2014, Article ID 867108, 11 pages, 2014.

[29] H. H. Nakajima, W. Dong, E. S. Olson, S. N. Merchant, M. E. Ravicz, and J. J. Rosowski, "Differential intracochlear sound pressure measurements in normal human temporal bones," Journal of the Association for Research in Otolaryngology, vol. 10, no. 1, pp. 23-36, 2009.

[30] Y.-J. Yoon, S. Puria, and C. R. Steele, "Intracochlear pressure and derived quantities from a three-dimensional model," Journal of the Acoustical Society of America, vol. 122, no. 2, pp. 952-966, 2007. 
[31] E. S. Olson, "Observing middle and inner ear mechanics with novel intracochlear pressure sensors," Journal of the Acoustical Society of America, vol. 103, no. 6, pp. 3445-3463, 1998.

[32] M. E. Ravicz, M. C. C. Slama, and J. J. Rosowski, "Middleear pressure gain and cochlear partition differential pressure in chinchilla," Hearing Research, vol. 263, no. 1-2, pp. 16-25, 2010.

[33] M. E. F. Niesten, C. Stieger, D. J. Lee et al., "Assessment of the effects of superior canal dehiscence location and size on intracochlear sound pressures," Audiology and Neurotology, vol. 20, no. 1, pp. 62-71, 2015.

[34] H. H. Nakajima, W. Dong, E. S. Olson, J. J. Rosowski, M. E. Ravicz, and S. N. Merchant, "Evaluation of round window stimulation using the floating mass transducer by intracochlear sound pressure measurements in human temporal bones," Otology and Neurotology, vol. 31, no. 3, pp. 506-511, 2010.

[35] C. Stieger, J. J. Rosowski, and H. H. Nakajima, "Comparison of forward (ear-canal) and reverse (round-window) sound stimulation of the cochlea," Hearing Research, vol. 301, pp. 105114, 2013.

[36] R. Z. Gan, R. K. Dyer, M. W. Wood, and K. J. Dormer, "Mass loading on the ossicles and middle ear function," Annals of Otology, Rhinology and Laryngology, vol. 110, no. 5, pp. 478-485, 2001.

[37] R. Z. Gan, M. W. Wood, and K. J. Dormer, "Human middle ear transfer function measured by double laser interferometry system," Otology and Neurotology, vol. 25, no. 4, pp. 423-435, 2004.

[38] S. Puria, W. T. Peake, and J. J. Rosowski, "Sound-pressure measurements in the cochlear vestibule of human-cadaver ears," Journal of the Acoustical Society of America, vol. 101, no. 5, part 1, pp. 2754-2770, 1997.

[39] R. Aibara, J. T. Welsh, S. Puria, and R. L. Goode, "Human middle-ear sound transfer function and cochlear input impedance," Hearing Research, vol. 152, no. 1-2, pp. 100-109, 2001.

[40] G. Von Bekesy, Experiments in Hearing, McGraw-Hill, New York, NY, USA, 1960.

[41] M. Kringlebotn, T. Gundersen, A. Krokstad, and O. Skarstein, "Noise-induced hearing losses. Can they be explained by basilar membrane movement?" Acta Oto-Laryngologica, Supplement, vol. 360, pp. 98-101, 1979.

[42] B. Feng and R. Z. Gan, "Lumped parametric model of the human ear for sound transmission," Biomechanics and Modeling in Mechanobiology, vol. 3, no. 1, pp. 33-47, 2004.

[43] J. E. Lupo, K. Koka, B. J. Hyde, H. A. Jenkins, and D. J. Tollin, "Physiological assessment of active middle ear implant coupling to the round window in Chinchilla lanigera," OtolaryngologyHead and Neck Surgery, vol. 145, no. 4, pp. 641-647, 2011.

[44] A. Arnold, C. Stieger, C. Candreia, F. Pfiffner, and M. Kompis, "Factors improving the vibration transfer of the floating mass transducer at the round window," Otology and Neurotology, vol. 31, no. 1, pp. 122-128, 2010.

[45] R. L. Sherbecoe and G. A. Studebaker, "Audibility-index functions for the connected speech test," Ear and Hearing, vol. 23, no. 5, pp. 385-398, 2002.

[46] C. V. Pavlovic, "Derivation of primary parameters and procedures for use in speech intelligibility predictions," Journal of the Acoustical Society of America, vol. 82, no. 2, pp. 413-422, 1987.

[47] E. G. Wever and M. Lawrence, Physiological Acoustics, Princeton University Press, Princeton, NJ, USA, 1982.
[48] D. R. Ketten, M. W. Skinner, G. Wang, M. W. Vannier, G. A. Gates, and J. G. Neely, "In vivo measures of cochlear length and insertion depth of nucleus cochlear implant electrode arrays," Annals of Otology, Rhinology \& Laryngology Supplement, vol. 175, pp. 1-16, 1998.

[49] M. J. Wittbrodt, C. R. Steele, and S. Puria, "Developing a physical model of the human cochlea using micro-fabrication methods," Audiology and Neurotology, vol. 11, no. 2, pp. 104-112, 2006.

[50] F. Böhnke and W. Arnold, "3D-finite element model of the human cochlea including fluid-structure couplings," $O R L$, vol. 61, no. 5, pp. 305-310, 1999.

[51] N. Kim, K. Homma, and S. Puria, "Inertial bone conduction: symmetric and anti-symmetric components," Journal of the Association for Research in Otolaryngology, vol.12, no. 3, pp. 261279, 2011. 


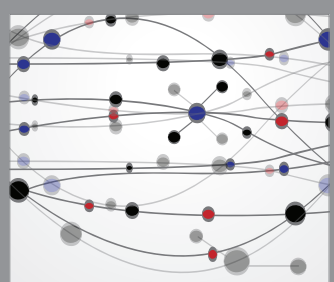

The Scientific World Journal
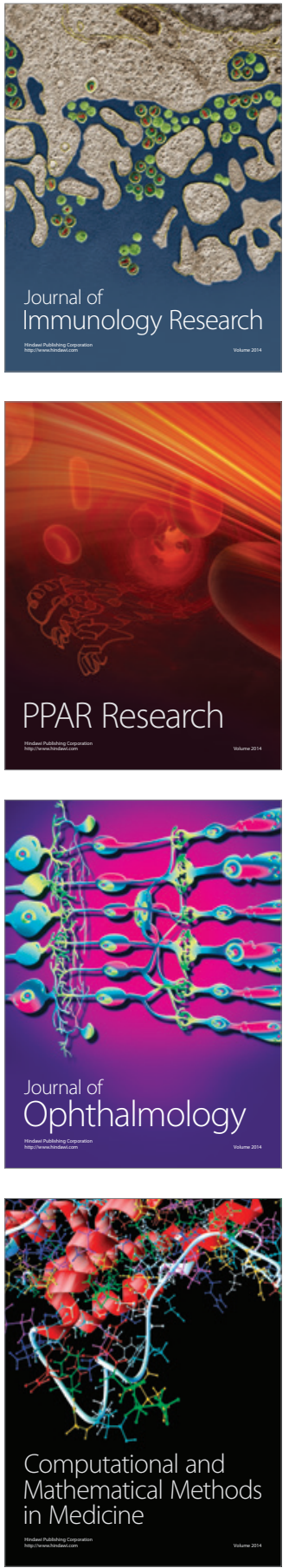

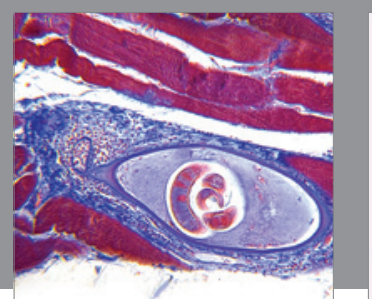

Gastroenterology Research and Practice

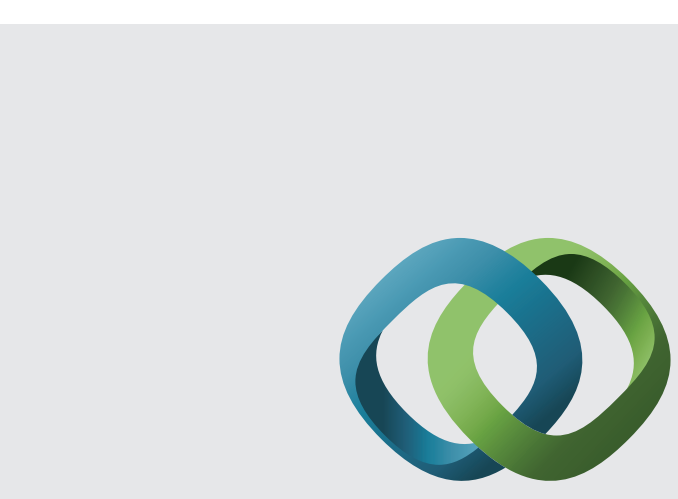

\section{Hindawi}

Submit your manuscripts at

http://www.hindawi.com
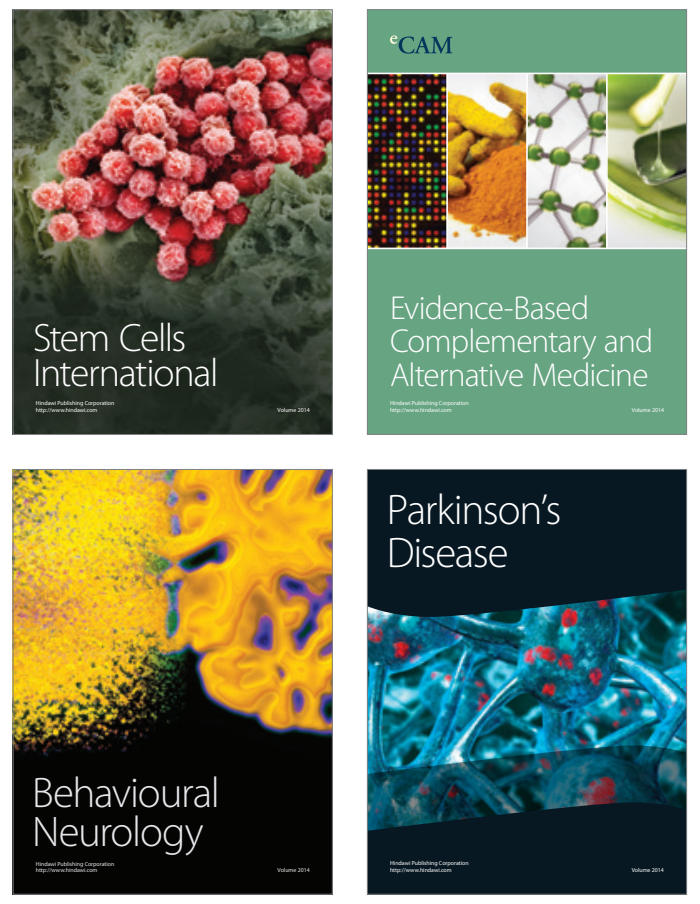
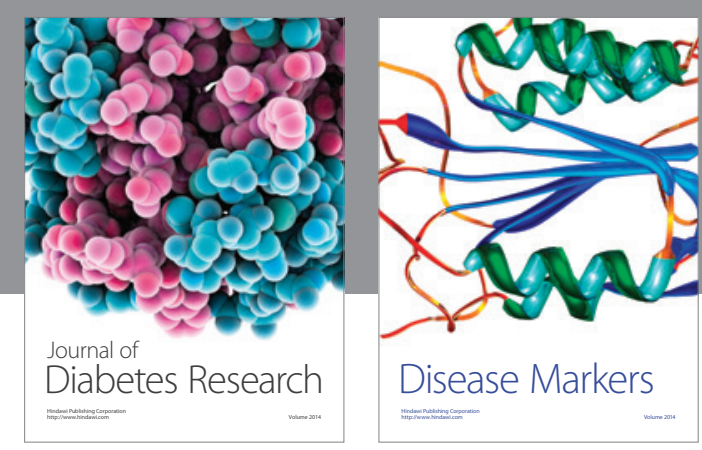

Disease Markers
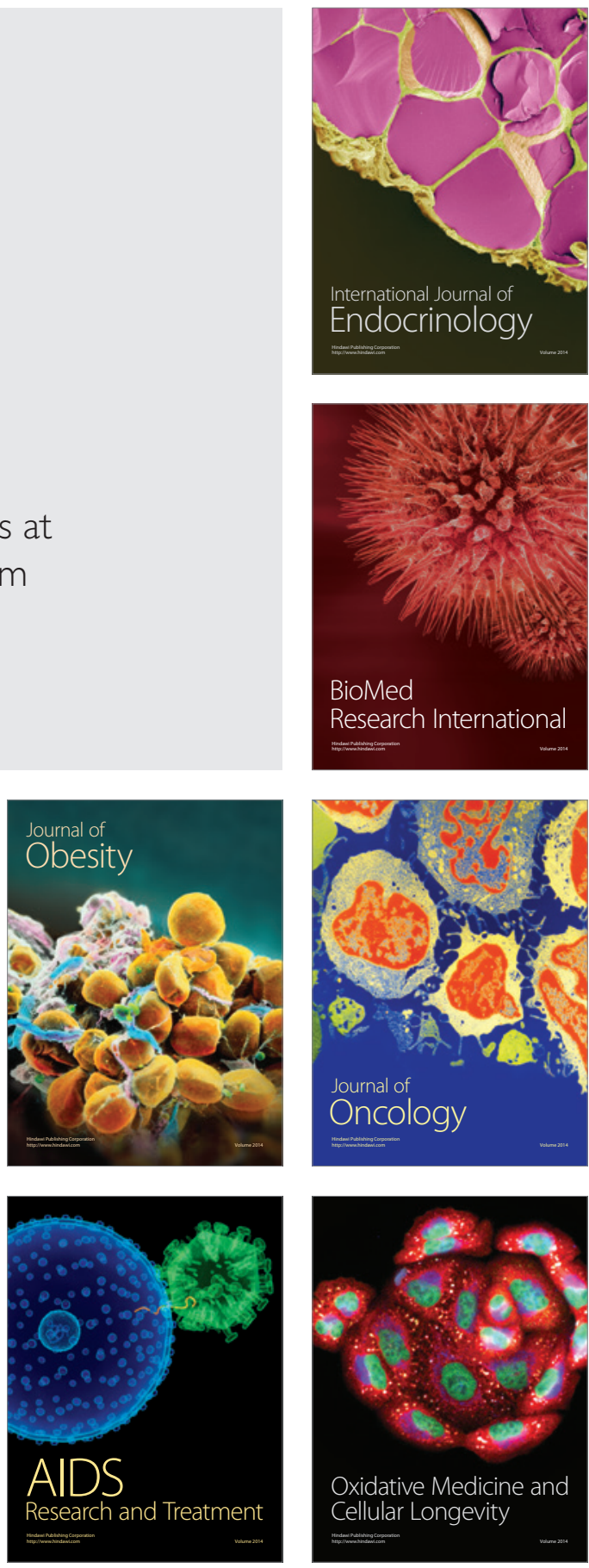